\title{
COMPARATIVE STUDY BETWEEN PROTAPER NEXT AND 2 SHAPE Ni-Ti ROTARY FILES ON MAINTANENCE OF CANAL CURVATURE USING RADIOVISIOGRAPHY (RVG) (AN IN VITRO STUDY)
}

\author{
Hajer Mohammed Abd El Hamid *
}

\begin{abstract}
Background: The main objective of the root canal preparation is to develop a continuous taper from coronal to apical with maintaining the original shape and curvature of the canal. During continuous development and manufacturing of nickel-titanium (Ni-Ti) alloys, there was a significant improvement of quality of rotary files to maintain the original root canal curvature with predictable results with less changes and iatrogenic damage.
\end{abstract}

Aim: The aim of this study was to evaluate and compare the maintenance of canal curvature using ProTaper Next and 2 Shape rotary Ni-Ti file system in shaping the apical third of the root canal using RadioVisoGraphy (RVG) on curved root canals.

Materials and Methods: Sixty extracted human permanent mandibular molar with mature apices and $30^{\circ}-40^{\circ}$ apical root curvature were collected and divided into two groups thirty teeth in each ; Group I : canals prepared using 2Shape NiTi rotary file system; Group II: canals prepared using ProTaper Next (PTN) rotary Ni-Ti file system. All samples were radiographed before and after preparation using RVG. The data collected were evaluated using the Student t-test.

Results: It was observed that Group I (2Shape) showed maintenance of canal curvature and lower percentage changes in canal curvature as compared to Group II (ProTaper Next) with no significant differences between the two groups

Conclusion: It was concluded that 2 Shape rotary $\mathrm{Ni}-\mathrm{Ti}$ system maintain the original canal curvature in comparison to ProTaper next rotary file system in curved root canal.

KEYWORDS: Maintenance of canal curvature, RadioVisoGraphy (RVG), ProTaper Next nickel-titanium rotary files, 2 Shape rotary $\mathrm{Ni}$-Ti files.

\footnotetext{
* Endodontic Department - MTI University - Cairo- Egypt
} 


\section{INTRODUCTION}

Among the last decade, there have been numerous protocols and techniques for preparing root canals to achieve a continues taper from apical to coronal, maintaining the original canal shape and curvature without errors. ${ }^{[1]}$

The improvement in the design of the file, the number of instruments and techniques advocated, endodontic treatment has been approached with optimum canal shape especially in curved root canals preserving the original canal shape. Several procedural errors can occur during shaping of curved root canals, including apical transportation, zipping, ledges, loss of working length, straightening of root canals, or deviation from original path. ${ }^{[2]}$

Since 1993 numerous Ni-Ti instrument systems was introduced to the market. They are classified according to their design, shaping characteristics, breakage potential, and clinical performance from generation $1^{\text {st }}$ to generation $5^{\text {th }} \cdot{ }^{[3]}$ The ability to maintain the shape of curved root canal is the most important feature of $\mathrm{Ni}-\mathrm{Ti}$ rotary instrument thus preserving the canal original shape ${ }^{[4]}$. A lower modulus of elasticity allows Ni-Ti rotary files to be placed in curved root canals with less lateral force exerted against the root canal walls. ${ }^{[5]}$

Maintenance of canal curvature of different rotary $\mathrm{Ni}$-Ti files have been compared by different methods including radiovisiography (RVG), it is a noninvasive technique for determining canal geometry and the accuracy and efficiency of NiTi rotary file system and shaping techniques. ${ }^{[6]}$ Using RVG, it is possible to compare the anatomic structure of root canal before and after root canal preparation.

Investigations of the shaping effect of these new $\mathrm{Ni}-\mathrm{Ti}$ systems with different design features and kinematics are important for understanding how the differences affect their performance to the best of our knowledge.
ProTaper Next (PTN; Dentsply Maillefer, Ballaigues, Switzerland) is a relatively new system. PTN instruments are made of M-wire, a unique NiTi alloy manufactured by a thermal treatment process that reportedly increases flexibility and resistance to cyclic fatigue ${ }^{[7,8]}$. These instruments incorporate a variable regressive taper design, unique offset mass of rotation, and rectangular cross section, which according to the manufacturer are designed to reduce points of contact with the canal walls generating less fatigue in the instrument during use.

Recently introduced, 2Shape (Micro-Mega, Besançon, France),NiTi rotary file is made of NiTialloy called T-wire. 2Shape is a sequence with 2 shaping files in continuous rotation which have been heat-treated using the T-Wire technology. The instruments' flexibility provides user comfort and an outstanding negotiation of curvatures. The instruments return to their initial shape after each use. ${ }^{[9]}$

The present study was conducted to compare the maintenance of canal curvature of two different newer rotary Ni-Ti file system, i.e., Protaper Next (PTN) Densply and 2 Shape rotary NiTi file systemMicromega in curved root canal.

\section{MATERIALS AND METHODS}

\section{Selection of teeth}

Sixty human lower mandibular first molars with moderate mesial root canal curvature ranging from $25^{\circ}$ to $40^{\circ}$ have been selected to be used in this study. The selected teeth were cleaned from soft tissue debris, blood and calculus by aid of ultrasonic scaler and were kept in sodium hypochlorite $5.25 \%$ solution for $1 / 2$ hours to remove any soft tissue and organic debris. The teeth then were stored in $0.9 \%$ normal saline solution till the time of use. Selected teeth were with mature apices without any noticeable defects. Each tooth was radiographed with RVG (Vatech Co., Ltd., Korea) in buccolingual 
and mesiodistal view in order to detect any possible root canal obstruction, internal resorption. Using a special image analysis program to analyze the curvature angle of the root canals (EasyDent V4 Viewer v. 4.1.5.0, Vatech Co., Ltd., Korea). The 60 teeth were divided in two groups, according to the rotary files system used for shaping the canal

A three clear plexiglas slides ${ }^{[10]}$ each slide was $4 \mathrm{~mm}$ in thickness snapped on top of each other and glued together and then a hole was drilled from the upper most slide though the others and then the extracted tooth were secured with the held of cold cured acrylic after removal of the distal root parallel to their long axis using servior. This Plexiglas is used as a guide during measuring with the Radio Visio Graph (RVG) because in each 4mm a radiopaque line appears. A radiographic platform was made to standardize the alignment of the teeth, Radio Visio Graph RVG sensor and the radiographic beam Figure (1). A muffle block was constructed consisting of two lateral walls and a middle $U$ shaped section fixed together with 3 screws, 2 in one of the lateral walls and 1 in the other.

A modification of the radiographic platform as described by Iqbal ${ }^{[11]}$ adjusted to the outer side of the middle part which may be replaced by a ring Figure (1) putting the cone in it to allow taking

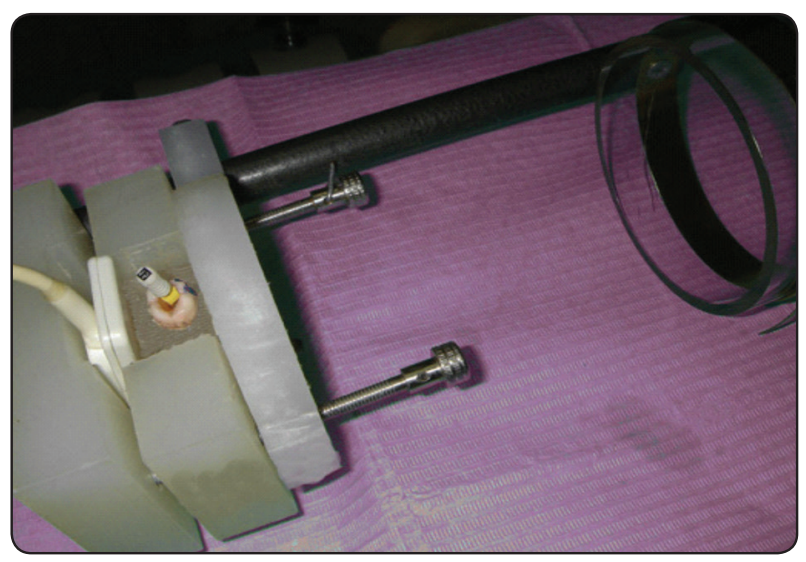

Fig. (1) Demonstrating the alignment of the tooth, RVG sensor and radiographic beam radiographs under standardized condition. On the other side there is a depression in the middle of the wall to facilitate putting the RVG sensor in it so that the primary beam is at right angle to the long axis of the radiographs. The samples from both facial and proximal views had been manipulated and saved in image software.

The pre-instrumentation digital radiograph taken to the canals with K- file \# 10 and the curvature of each canal was measured by using Schneider's method.

After the digital radiographs downloaded in computed image analysis software to measure the original canal curvature and the K-FILE was used as an indicator to measure the curvature and orientation throughout the length of the root.

According to Schneider's method ${ }^{[12,13]}$ the angles were measured by using the image software and choosing the (angle of a segment) icon to measure it on the radiograph. A straight line was traced with the mouse pointer through the outline of the file from the apex. The other straight line was determined by tracing a straight line through the outline of the file in the coronal portion of the curve. The intersection of these two lines forms an interior angle which represents the degree of root curvature.

A standard endodontic coronal access cavity was done in all teeth using high-speed round, long neck diamond burs (Dentsply Maillefer, Ballaigues, Switzerland). Endo Z burs (Dentsply Maillefer) completed the coronal flaring. Irrigation was performed with $5 \mathrm{~mL}$ of $5.25 \% \mathrm{NaOCl}$. Afterwards, a size \#10 K-file ISO (Dentsply Maillefer) was used for canal patency in the mesiobuccal canal; we were able to determine the working length (WL) by subtracting $1 \mathrm{~mm}$ from the visible tip of the file at the apical foramen level; then a glide path was established to size \#10 K-file a pre-instrumentation digital radiograph were taken for the root canals then measuring the canal curvature before shaping of the canals . Based on the rotary files system 
used in shaping the canals, the teeth were randomly assigned to two experimental groups: - Group I: 2Shape (\#25/06) (MicroMéga, Besançon, France). - Group II: Pro Taper Next (Dentsply Maillefer, Ballaigues, Switzerland) (PTN) till X2 (\#25/06); The pulp chamber was filled with $5.25 \% \mathrm{NaOCl}$ throughout instrumentation.

In Group I, after the canals were first negotiated with \#10 K-files (Dentsply Maillefer) for patency then irrigated and introduced to the working length then root canal preparation was performed to the working length in rotation motion using TS1 (\#25/ $0.04)$ and then TS2 (\#25/ 0.06) 2Shape rotary file ${ }^{[9]}$

In Group II, once a \#10 Stainless steel K-file was confirmed loose at length the PTN X1(\#17/ 0.4) file was used to prepare the root canals following the glide path, until a full working-length was reached. After the canal was irrigated, \#10 K-file was again used to recapitulate to break up residual debris and move it by irrigation. The next file used was PTN X2 (\#25/ 0.6) until the working length also. The apical foramen in the mesiobuccal canals was determined to be a \#25/06 size ${ }^{[14]}$

\section{Assessment of the root canal instrumentation}

The prepared canals were radiographed by RadioVisioGraphy (RVG) from the facial and proximal view using the muffle system to obtain a standardized imaging with the file inside the canal. Pre- and post-instrumentation comparisons of images were obtained to evaluate the canal curvature accurately. The digital image which is taken by RVG were measured before and after instrumentation according to Schneider's method using a image software (computed image analysis software) by drawing a central line in the canal from the coronal part and other line from the apex of the canal and the difference changes in the angles were recorded directly on a coding sheets and then stored and tabulated in the PC using Microsoft Excel then the data were statistically analyzed. All data was reported as mean \pm standard deviation $(\mathrm{SD})$. The statistical analysis was completed with Statistical Package for the Social Sciences (SPSS). The significance level was set at $95 \%$ for all tests. The independent sample Student's t-test (two-tailed) was used to compare the pre and post-preparation parameters between the groups.

\section{RESULTS}

Table 1 showed the mean \pm SD of preinstrumentation and post-instrumentation in mesiobuccal root canals of the mandibular first molars with 2Shape and ProTaper Next using RVG digital radiography in mesiodistal and buccolingual view.

Mean and standard deviation values for pre- and post-instrumentation, the change and percentage change in PTN and 2Shape groups were measured, tabulated and statistically analyzed by t-student test for the mesiodistal and buccolingual views; Tables (1)

The percentage change in original canal curvature was higher in PTN group $11.082 \%$ than 2Shape group $6.793 \%$ in mesiodistal view and $13.939 \%$ for PTN group and $11.142 \%$ for 2Shape group in buccolingual view with no statistical significant changes $(p>0.05)$ between the groups. The mean value in the two groups decreases after instrumentation

\section{DISCUSSIONS}

The Nickel titanium alloys have been found that it is 2-3 times more elastic than stainless steel files. This allows an great advantages to $\mathrm{Ni}$-Ti files in preparing curved canals with less lateral stress and errors during cleaning and shaping with enhanced shaping quality and respecting to the original canal anatomy.$^{[15]}$

Many previous studies have shown the effectiveness of Ni-Ti files to maintain the original canal shape minimizing the risk of canal changes with lower incidence of straightening of canal 
TABLE (1): Mean \& SD of Pre- and Postinstrumentation of (2Shape and PTN) and the change and percentage change in mesiodistal and buccolingual views

\begin{tabular}{|c|c|c|c|c|}
\hline & $\begin{array}{l}\text { Pre- } \\
\text { Instrumentation }\end{array}$ & $\begin{array}{l}\text { Post- } \\
\text { Instrumentation }\end{array}$ & $\begin{array}{l}\text { The } \\
\text { Change }\end{array}$ & $\begin{array}{l}\text { The Percentage } \\
\text { Change }\end{array}$ \\
\hline \multicolumn{5}{|c|}{ MESIODISTAL VIEWS } \\
\hline \multicolumn{5}{|c|}{ GROUP I (2Shape) } \\
\hline MEAN & $25.17^{\circ}$ & $23.46^{\circ}$ & $1.7^{\circ}$ & $6.793 \%$ \\
\hline SD & $+/-2.431$ & $+/-1.81^{\circ}$ & $+/-0.621$ & $+/-2.426$ \\
\hline \multicolumn{5}{|c|}{ GROUP II (PTN) } \\
\hline MEAN & $23.10^{\circ}$ & $20.54^{\circ}$ & $2.56^{\circ}$ & $11.082 \%$ \\
\hline SD & $+/-2.58$ & $+/-1.913$ & $+/-0.667$ & $+/-3.957$ \\
\hline \multicolumn{5}{|c|}{ BUCCOLINGUAL VIEW } \\
\hline \multicolumn{5}{|c|}{ GROUP I (2Shape) } \\
\hline MEAN & $17.95^{\circ}$ & $15.95^{\circ}$ & $2^{\circ}$ & $11.142 \%$ \\
\hline SD & $+/-5.586$ & $+/-4.796$ & $+/-1.747$ & $+/-3.979$ \\
\hline \multicolumn{5}{|c|}{ GROUP II (PTN) } \\
\hline MEAN & $18.15^{\circ}$ & $15.62^{\circ}$ & $2.53^{\circ}$ & $13.939 \%$ \\
\hline SD & $+/-5.216$ & $+/-5.367$ & $+/-0.151$ & $+/-4.978$ \\
\hline
\end{tabular}

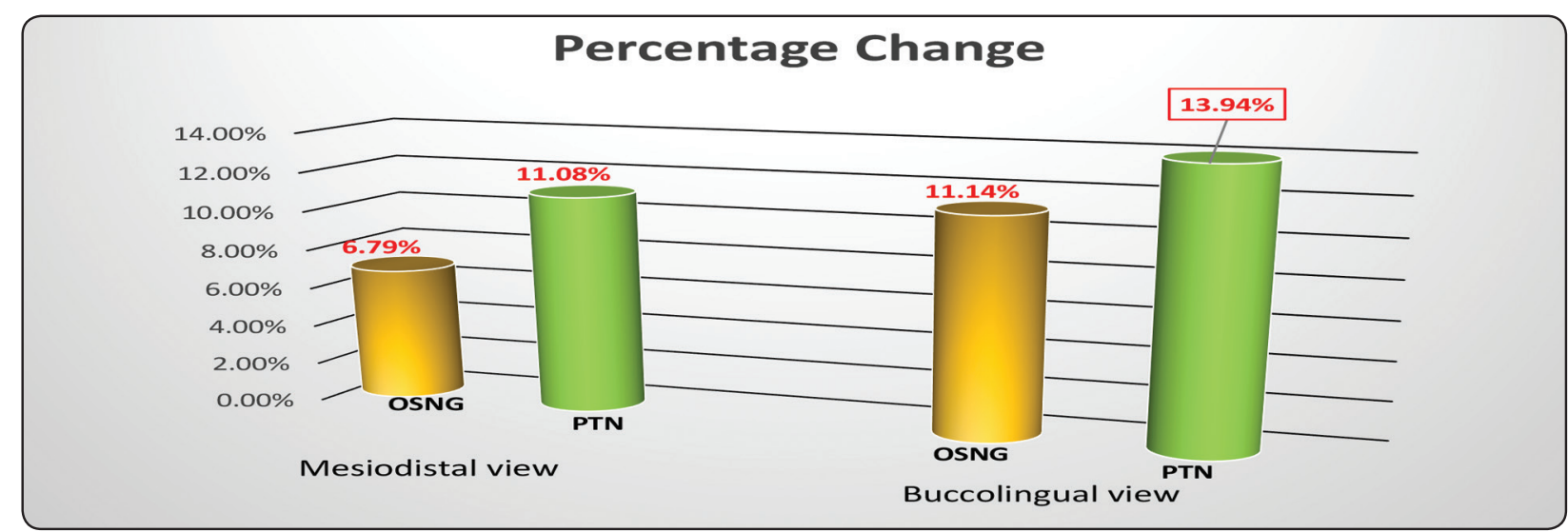

Graph [1] The chart demonstrating the percentage change in canal curvature after canal instrumentation using ProTaper Next and 2Shape rotary Ni-Ti files

curvature, the formation of ledges and irregular apical enlargement. ${ }^{[16-18]}$. In addition of canal anatomy, other factors contribute to the optimal outcomes after mechanical instrumentation, such as instrument design and the system sequence ${ }^{[19]}$, rotational speed, operator's experience and the use of irrigants and lubricants during preparation of root canal.

The unique swaggering movement and the greater flexibility of the ProTaper Next files make it possible to shape more severely curved narrow 
canals than what was possible before with most NiTi systems, respecting the original root canal anatomy. The risk of file breakage is significantly decreased due to the M-Wire NiTi material improves file flexibility, while still retaining cutting efficiency and decrease the tendency to file fracture . ProTaper Next has an increasing and decreasing tapers and innovative off-centred rectangular cross section gives the file a snake-like "swaggering" movement as it moves through the root canal. The off-centred cross section and the unique design of the file generate enlarged space for debris hauling. ${ }^{[20]}$

2 shape has the latest generation of asymmetrical cross section with triple helix: two primary cutting edges and 1 secondary cutting edge aids in perfect compromise between cutting efficiency and debris removal.

2 Shape is a T-Wire rotary file systemreduces the risk of instrument fracture andincreases the efficacy of the circumferential brushing movements for efficient selective cleaning and shaping of the root canal with respect to the original morphology of the root canal due to the new wire treatment method. This could be attributed to the metallurgy of 2Shape NiTi rotary file which works on rotating motion and is made of NiTi-alloy called "T-wire" which is a method which allows for increased resistance to cyclic fatigue $(+40 \%)$ and a better negotiation of curvatures. The two instruments (TS1 and TS2) return to their original shape after each use. ${ }^{[9]}$

This study evaluated the changes occurred in root canal curvature of the mesiobuccal canal in the lower first molars after they were instrumented with two Ni-Ti rotary systems using RVG. The systems used in this research were (2 Shape) and (ProTaper Next) rotary files. Previous studies demonstrated that ProTaper Next obtains less invasive preparation and a homogenous increase in canal taper [21]. Studies showed that the design of the instrument affects the shaping ability of Ni-Ti system ${ }^{[22]}$ while others showed the opposite ${ }^{[23]}$. In this study, there were no significant difference in the maintenance of canal curvature of the root canals comparing the two rotary systems. The increase in these parameters is slightly higher for ProTaper next in mesiodistal and buccolingual view $(2.65 \%$ and $2.53 \%$, respectively) than for 2 Shape (1.7\% and $2 \%$, respectively), this is explained by the fact that the 2 Shape has a constant taper of 0.06, while the ProTaper Next has a variable taper ${ }^{[24]}$. This is in accordance with earlier considerations ${ }^{[25,26]}$ that demonstrated that the two systems remove similar amounts of dentin when instrumenting root canal during shaping and cleaning. The change in root-canal shape after PTN instrumentation was minimal in other studies [27], and the values were close to those obtained in our study.

Studies showed that M-Wire had physical and mechanical properties that can render root canal instruments more flexible and resistant to fracture than those made from conventionally martensitic NiTi ${ }^{[28]}$

M-wire $\mathrm{NiTi}$ is characterized by superior flexibility and maintenainng root canal original anatomy compared with conventional NiTi rotary files ${ }^{[29]}$

\section{CONCLUSIONS}

This study shows that the shaping ability of the two Ni-Ti rotary systems is similar, they maintain the original canal curvature during instrumentation of root canals. The comparison between the two groups did not show a significant difference ( $p>0.05)$ in maintenance of canal curvature of the root canals.

\section{REFERENCES}

1. Kuzekanani M, Walsh LJ, Yousefi MA. Indian J Dent Res 2009, ;20(3):268-70.

2. Versiani MA, Pascon EA, de Sousa CJ, Borges MA, SousaNeto MD. Influence of shaft design on the shaping ability of 3 nickel-titanium rotary systems by means of 
spiral computerized tomography. Oral Surg Oral Med Oral Pathol Oral Radiol Endod, 2008, 105(6):807-813.

3. Haapasalo M, Shen Y. Evolution of nickel-titanium instruments: from past to future. Endod Topics, 2013, 29(1):3-17.

4. Bramante CM, Berbert A, Borges RP. A methodology for evaluation of root canal instrumentation. J Endod, 1987, 13(5):243-245.

5. Schäfer E \& Dammaschke T. Comparative study on the shaping ability and cleaning efficiency of rotary Mtwo instruments. Part 2. Cleaning effectiveness and shaping ability in severely curved root canals of extracted teeth. Int Endod J, 2006, 39(2); 203-212.

6. Li X, Liu N, Liu R, Dong Z, Liu L, Deng M. Comparative study of root canal morphology of mandibular first premolar by micro-CT and radiovisiography. 2012, 30(1):57-60.

7. Gao Y, Gutmann JL, Wilkinson K, et al. Evaluation of the impact of raw materials on the fatigue and mechanical properties of ProFile Vortex rotary instruments. J Endod 2012;38:398-401.

8. Ye J, Gao Y. Metallurgical characterization of M-Wire nickel-titanium shape memory alloy used for endodontic rotary instruments during low-cycle fatigue. J Endod 2012;38:105-7

9. Micro Mega, France. 2 Shape. Available from: http:// micromega.com/shaping/2shape

10. Hülsmann M, Armin Gambal, and Rdiger Bahr. An Improved Technique for the Evaluation of Root Canal Preparation. J Endod,1999, 25(3); 599-603.

11. Iqbal M. K., Francesco Maggiore, Brian Suh, Kevin R. Edwards, Jamie Kang, Syngcuk Kim and Phil M. Comparison of Apical Transportation in Four Ni-Ti Rotary Instrumentation Techniques. J Endod, 2003, 29(1); 587-590.

12. Schnieder WE. A comparison of canal preparations in straight and curved root canals. Oral Surg 1971; 32: 27-5.

13. Günday M1, Sazak H, Garip Y. A comparative study of three different root canal curvature measurement techniques and measuring the canal access angle in curved canals. JEndod. 2005, 31(11):796-8.

14. Koçak MM, Çiçek E, Koçak S, Sağlam BC, Yılmaz N. Apical extrusion of debris using ProTaperUniversal and ProTaperNext rotary systems. Int Endod J. 2015, 48(3):283-6.
15. Hulsmann M, Peters OA, Dummer PM. Mechanical preparation of root canals: shaping goals, techniques and means. Endod Top 2005; 10:30-76.

16. Kandaswamy D, Venkateshbabu N, Porkodi I, Pradeep G. Canal-centering ability: An endodontic challenge. J Conserv Dent. 2009; 12:3-9.

17. Loizides AL, Kakavetsos VD, Tzanetakis GN, Kontakiotis EG, Eliades G. A comparative study of the effects of two nickel-titanium preparation techniques on root canal geometry assessed by microcomputed tomography. J Endod. 2007, 33:1455-9.

18. Jafarzadeh H, Abbott PV. Ledge formation: Review of a great challenge in endodontics. J Endod. 2007, 33:115562.

19. Moore J, Fitz-Walter P, Parashos P. A micro-computed tomographic evaluation of apical root canal preparation using three instrumentation techniques. Int Endod $\mathrm{J}$. 2009;42:1057-64.

20. Pasqualini D, Alovisi M, Cemenasco A, Mancini L, Paolino DS, Bianchi CC, Roggia A, Scotti N, Berutti E. Micro-computed tomography evaluation of ProTaper Next and BioRace shaping outcomes in maxillary first molar curved canals. J Endod, 2015, 41(10):1706-1710.

21. Elnaghy AM, Elsaka SE. Assessment of the mechanical properties of ProTaperNext Nickel-titanium rotary files. JEndod. 2014 Nov; 40(11):1830-4.

22. Capar ID, Ertas H, Ok E, Arslan H, Ertas ET, Comparative study of different novel nickel-titanium rotary systems for root canal preparation in severely curved root canals. J Endod, 2014, 40(6):852-856.

23. Bergmans L, Van Cleynenbreugel J, Beullens M, Wevers M, Van Meerbeek B, Lambrechts P. Progressive versus constant tapered shaft design using NiTi rotary instruments . Int Endod J, 2003, 36(4):288-295.

24. Gagliardi J, Versiani MA, de Sousa-Neto MD, PlazasGarzon A, Basrani B. Evaluation of the shaping characteristics of ProTaper Gold, ProTaper Next, and ProTaper Universal in curved canals. J Endod, 2015, 41(10):1718-1724.

25. Pasqualini D, Alovisi M, Cemenasco A, Mancini L, Paolino DS, Bianchi CC, Roggia A, Scotti N, Berutti E. Micro-Computed Tomography Evaluation of ProTaper Next and BioRace Shaping Outcomes in Maxillary First Molar Curved Canals.2015, 41(10):1706-10. 
26. Burklein S, Mathey D, Schafer E. Shaping ability of ProTaper Next and BT-RaCe nickeltitanium instruments in severely curved root canals. Int Endod J 2015; 48:774-81.

27. Wu H, Peng C, Bai Y, et al. Shaping ability of ProTaper Universal, WaveOne and ProTaper Next in simulated L-shaped and S-shaped root canals. BMC Oral Health 2015; 15:27.
28. Pereira ESJ, Peixoto IFC, Viana ACD. Physical and mechanical properties of a thermomechanically treated NiTi wire used in the manufacture of rotary endodontic instruments. International Endodontic Journal 2012;45, 469-74

29. Shen Y, Cheung GS, Bian Z, Peng B. Comparison of defects in ProFile and ProTaper systems after clinical use. Journal of Endodontics 2006;32, 61-5. 